\title{
Particle Flow Simulation of Effect of Pushing Against Soil of Static Driven Piles
}

\author{
CHEN Wen zhao ${ }^{1, a}$, HUANG Xin fei ${ }^{2, b}$, LIU XI qi ${ }^{3, c}$ \\ ${ }^{1}$ School of Nanhua, Nanhua University,hengyang 421000, China; \\ ${ }^{2}$ School of Nanhua, Nanhua University, hengyang 421000, China. \\ a729866737@qq.com
}

\section{Keywords: Particle flow code (PFC2D); Pile Driving; displacement; stress}

\begin{abstract}
Effect of pushing against soil of static driven Piles involve a series of problem, such as the large deformation and material non-linearity, etc. the research on its mechanism of action is still in the stage of exploration at present. In this paper, it attempts to analyze the problem of characteristic of development and change of stress and displacement in the process of extrusion and compaction of lateral soil of pile from the microscopic view when piles squeezed into soil. Based on the previous theoretical analysis and experimental results on the model, the two-dimensional particle flow code (PFC2D) is developed, the whole process of Static driven Piles continuous penetrate soil is simulated. The laws of soil displacements and stress changing with horizontal distance and depth during the process of pressing piles are obtained. Finally, the model results were compared with experimental results, and verified the applicability of the simulation results. In this paper, it reveals the regularity of movement of particles from the microscopic view in the process of static pressure piles Squeezed into soil, and it provide some reference for more complex microscopic simulation research of geotechnical engineering problems.
\end{abstract}

\section{Introduction}

Precast pile is a type of pile that is commonly used in pile foundation engineering. Producing pressure to the soil around the piles when piles driven into soil. Meanwhile, causing the soil around the pile has large horizontal and vertical displacement. The common method of precast pile pressed into soil has driven (including hammering and vibration) and static pressure pile sinking type etc. Among them, the driven is restricted to use for hammering and vibration often produce large noise, ground disturbance, exhaust gas and other pollution problems in the construction process .The static pressure pile in soft soil foundation is pressured into the soil by static pressure, because of its advantages of little noise, saving material, easy to ensure construction quality and so on, it has a wide application in the coastal soft soil area. However, the effect of soil squeezing during pile-driving can lead to many adjacent buildings or underground pipes, cables and other facilities in the city crowded buildings be damaged. As a result, the research on the soil compaction effect of pile foundation has been paid more and more attention, but the influence of adjacent pile caused by static pressure pile, surface doming and other issues still haunt the scientific research and engineering and technical personnel, also affects the better application of pile foundation in engineering. Because of the complexity of the problem of pile, people have carried out the study of this problem for a long time [1-5]. But most concentrated on the method created under the theory of continuous theory, from macro get analysis parameters, apply the theory of continuum mechanics and create analysis model, there are some problems often exist limitations, such as large deformation and materials nonlinear involved in the process of the pile driving effects.

Macroscopic mechanical properties of soil mainly depend on the microstructure. Internal structure of soil around the pile will change obviously when the pile pressured into the strong structural soft soil. Therefore, from the microscopic view to understand the mechanism of soil compaction effect has important theoretical and practical significance. So the author conducted the PFC2D particles flow program, using granular flow can simulate large deformation and the 
advantage of microscopic damage, overcome the problems and shortcomings existing in the traditional continuum mechanics model, get the changing rule of the stress field and displacement field of soil around piles. The research result is beneficial to analyze the soil compaction mechanism of static pressure pile jacked into soil, and useful to optimize the design and construction of pile in the engineering application.

\section{Numerical simulation of granular flow}

\subsection{Discrete element particle flow theory introduction and model selection.}

Discrete element method is to simulate the spread process of movement in the particle grains. Particle movement will inevitably cause collisions between particles, and the force must be produced between particles. According to the different contact, there are hard particle contact and soft particle contact in discrete element. Hard particles contact is assumed between particles will not produce significant plastic deformation when the stress of bearing surface is low. At the same time, we think that the collision between particles is instantaneous. Soft contact is commonly used to describe contact events in the discrete element method, that is to say, in a pair of contact points allowed overlap. A contact model associate the amount of overlap at contact point with the physical attributes of contact particle, related impact velocity, contact information before time step through a pair of equal and opposite force. Calculate the resultant force acting on the particle (including particle and contact forces), and then by Newton's second law and the contact force between particles and particle physical determine particle movement, to update the rate of movement of the particles and the position of the particle and the particle. Due to the soft particle contact model can absorb numerous contact models, and its execution time also has the advantage when the large number of system is simulated, therefore it has wide applicability.

PFC provides some main models, such as linear model, linear contact bond model, linear parallel bond model and Hertz model, etc. Only the reasonable particle contact force model is used, the simulated result of the granular flow is correct. In this paper, we only qualitatively study the microcosmic mechanism of static driven piles, the properties of displacement is different according to the different properties of soil in the process of jacked pile. To make the soil compaction effect is more apparent, in this paper, it simulate sensitivity high cohesive soil and use the parallel bond model. The model of parallel bond is bonded by flexible glue in the contact surface, which is rigidity and deformation, when the force is greater than the bond strength, it will wreck.

\subsection{The establishment of the static pile PFC model}

Due to the soil is not uniform, discontinuous, anisotropic geological body in nature, so, the whole project system has randomness, uncertainty. There is much difficulty if the system is simulated according to the actual situation, which is not necessary. Sand particles are idealized into spherical particles in this article, the purpose of constructing a rectangular sample is to meet the requirement of precision and the limited speed of calculation, and generate about 8000 soil particles. The model box is made up with 1.3 meters high, 2.4 meters wide, and three sections of wall. Model pile has length $1 \mathrm{~m}$, diameter $0.45 \mathrm{~m}$, tip length $0.08 \mathrm{~m}$, it is applied a corresponding speed along the y-direction and used to simulate the process of Piles continuous penetrate soil. Using a linear parallel bonding between the particles and the particles, the particles in contact with the wall using a linear model, the model structure parameters are shown in table 1.

\subsection{Monitoring of displacement and stress}

In order to obtain the changing law of displacement field, stress field and void ratio of soil around the pile in the process of piles jacked into soil, setting up a series of monitoring points and measuring circle in the model,. Among them, the monitoring point is mainly used to determine the displacement of soil around pile during the static pressure pile Squeezed into soil, and measuring coil is mainly used to detect the changing process of Horizontal stress of soil around the pile. 
Table 1. Meso Parameters of PFC Model

\begin{tabular}{|l|l|l|l|l|l|l|l|l|l|}
\hline Type & $\begin{array}{l}\text { Weight } \\
\text { of } \\
\text { particles } \\
(\mathrm{kg} / \mathrm{m} 3)\end{array}$ & $\begin{array}{l}\text { Radius } \\
\text { of } \\
\text { partices/ } \\
\mathrm{mm}\end{array}$ & $\begin{array}{l}\text { Amplificati } \\
\text { on } \\
\text { coefficient } \\
\text { of particle } \\
\text { size }\end{array}$ & $\begin{array}{l}\text { Tangent } \\
\text { stiffness } \\
\mathrm{ks} /(\mathrm{N} / \mathrm{m} \\
)\end{array}$ & $\begin{array}{l}\text { Normal } \\
\text { stiff-ness } \\
\mathrm{kn} /(\mathrm{n} / \mathrm{m})\end{array}$ & $\begin{array}{l}\text { The } \\
\text { coefficie } \\
\mathrm{nt \quad \text {of }} \\
\text { friction } \\
\mu)\end{array}$ & $\begin{array}{l}\text { Tensile } \\
\text { strengt } \\
\mathrm{h}\end{array}$ & $\begin{array}{l}\text { Cohesi } \\
\text { on }\end{array}$ & $\begin{array}{l}\text { Local } \\
\text { damp } \\
\text { ing }\end{array}$ \\
\hline $\begin{array}{l}\text { Soil } \\
\text { Particle } \\
\mathrm{s}\end{array}$ & 20.0 & $\begin{array}{l}0.125 ~ 0 . \\
15\end{array}$ & 1.2 & $1 \times 10^{8}$ & $1 \times 10^{8}$ & 0.577 & $2 \times 10^{5}$ & $2 \times 10^{5}$ & 0.7 \\
\hline $\begin{array}{l}\text { Model } \\
\text { box }\end{array}$ & & & & $1 \times 10^{7}$ & $1 \times 10^{7}$ & 0.09 & & & \\
\hline
\end{tabular}

2.4 Simulation of the whole process of jacked pile

Using above displacement monitoring method to measure the displacement of change of soil around pile, and gives the displacement nephogram and the vector diagram of displacement (Fig. 2-1, 2-2) of foundation soil.

In figure 2-1, (a) and (b) are respectively expressed as the displacement nephogram and the vector graph of soil around tip of pile. The figure shows: in the beginning stages of driven pile, the partial circular soil around the tip of pile produce plastic deformation, the vector diagram clearly shows the moving direction of the soil particle, and also illustrates the expansion trend of soil particles. The soil particle right and left side of the pile tip is dragged, and produce downward displacement along the pile shaft. The moving direction of soil particles under the end of pile reflects the trend of the soil expand all around under the action of the extrusion pressure. From figure 2-1 (c) displacement image can be seen, when the pile sinking is completed, the soil above the pile complete the wedge shape of the plastic sliding surface, extends to the surface. The soil in the pile tip appears pear-shaped plastic sliding surface (interface of blue and green), it is consistent with the Meyerhof (1959[7]) displacement pattern.

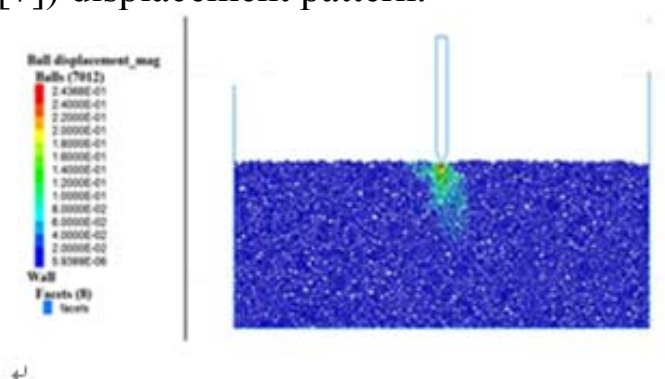

(a) The displacement nephogram $\mathrm{t}=100$

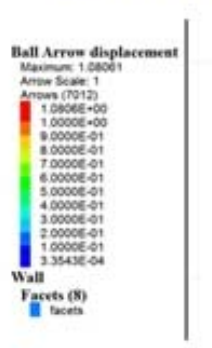

(c)The displacement nephogram $\mathrm{t}=20000$

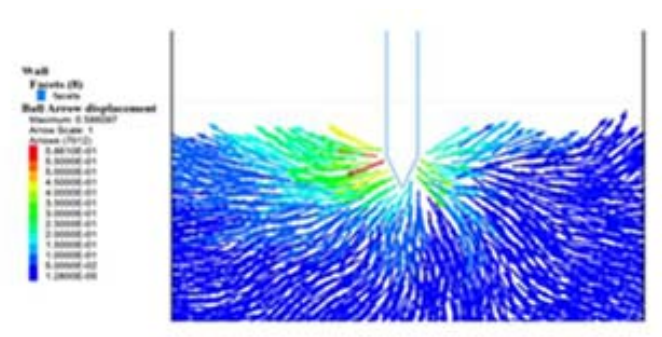

(b)The vector diagram of displacement $\mathrm{t}=100$

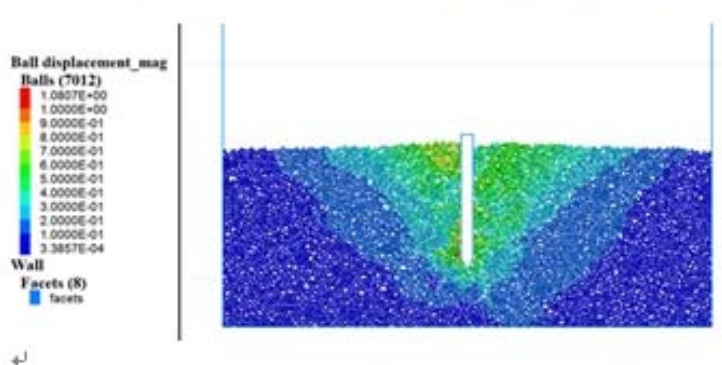

(d) The vector diagram of displacement $\mathrm{t}=20000$

Fig.2-1 .the displacement nephogram and the vector diagram of displacement

In the process of pile jacked into soil, the displacement of $\mathrm{X}$ and $\mathrm{Y}$ direction is symmetrically distributed on both sides of the pile, and can be seen that the displacement in X direction is mainly distributed in the soil above the pile tip, the displacement in Y direction is mainly distributed in the above shallow soil around pile and soil of the pile tip. Deformation of soil around the pile tip is similar to the deformation in $\mathrm{Y}$ direction which is caused by the expansion of a spherical cavity, And except 
for the soil near the pile tip and around the most of the pile, the deformation of soil is similar to the deformation in $\mathrm{X}$ direction which caused by the expansion of cylindrical cavity. The result is consistent with the cavity expansion theory which is researched by Vesic[2], the cylindrical cavity expansion theory which is proposed by Butterfield and Banerjee[9 10], and it also shows the model adaptability.

In the entire process pile sinking, we can see that the spherical soil which contact with pile tip has always maintained a downward displacement, and it's continuous extrusion surrounding soils. As the pile sank to a certain depth, upper soil based on both sides in the y direction displacement nephogram in apparent positive displacement value of instructions in pile foundation soil on both sides of the uplift, the deeper the pile sinking, the more powerful uplift, uplift and near-surface soil than in deep soil uplift is big, this is mainly due to the pile is located in the upper soil, due to come from the extrusion of soil around the pile and time together with this part of the soil is less affected by overlaying soil, produces the upward arch, and along with the deepening of soil, soil from the upper part of the role of pile soil increasing, limiting its upward displacement.

\section{Analysis of the simulative results}

\subsection{Displacement of radial direction}

As shown in Fig. 3-1 and Fig.3-2, is curves of relationship between radial displacement of the pile soil at different depths and the distance $r$ away from the side of pile in the process of jacked pile.From Fig.3-1,we can know that the lateral horizontal displacement of soil located at the upper part of the pile decreases exponentially with the growth of distance $r$. While the soil located at the top of pile increases first and then reaches a maximum of about $0.16 \mathrm{~cm}$ (about 3.5 percent of the diameter of the pile )when $\mathrm{r}=3 \mathrm{~cm}$. Then, the lateral displacement of soil decreases rapidly and tends to zero with the growth of distance $r$.

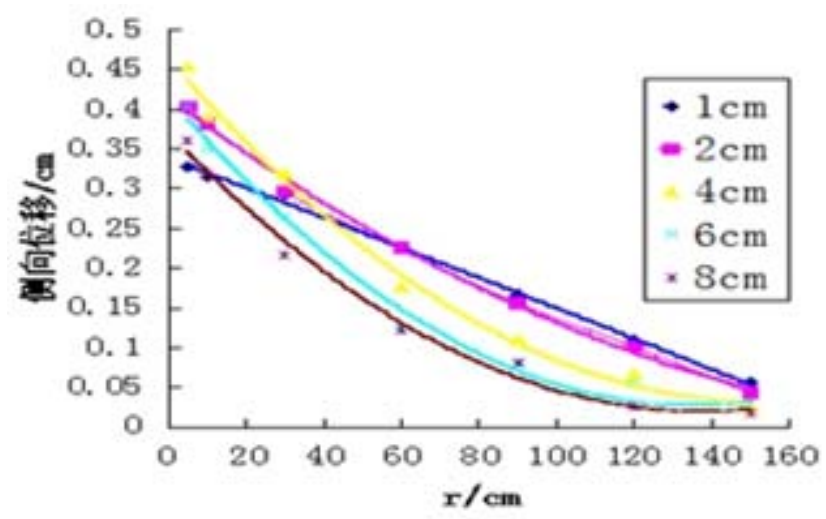

Figure 3-1 is curve of lateral displacement of the soil around the upper pile along variation of the radial

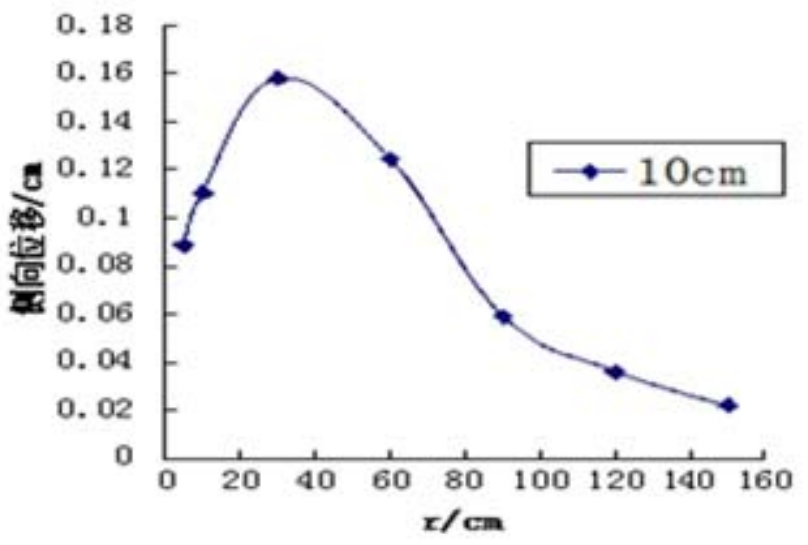

Figure 3-2 is curve of lateral displacement of the soil around the tip pile along variation of the radial 


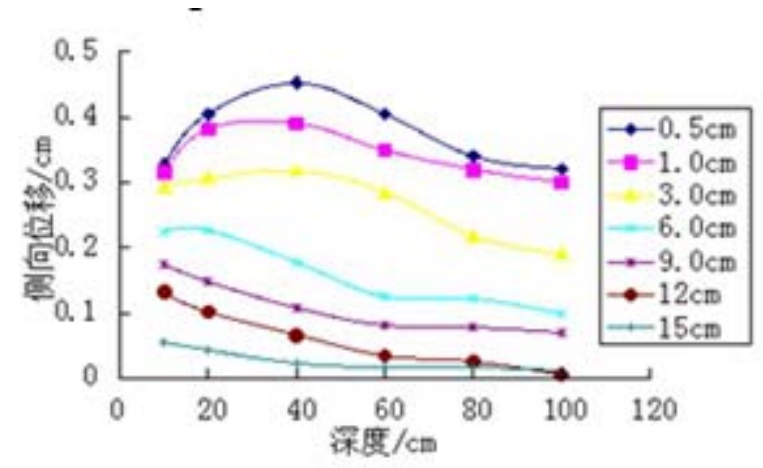

Figure 3-3 is curve of lateral displacement of the soil around

the pile along variation of direction of depth

As shown in Fig. 3-3, is a curve of relationship between lateral displacement of pile soil at different distances along the depth direction .From the Fig, we can know the main deformation characteristics of this part of soil :the displacement of soil near the pile showing a near pile, pile of small and middle far large saddle Distribution .The lateral horizontal displacement of soil located in the upper part of the pile reaches a maximum at a distance of about $3 \mathrm{~cm}$ away from pile diameter and then decreases with the growth of depth. While soil located at the far pile decreases and tends to zero From the results of model test recommended by JianPing Xu[8],we can know that the displacement curve of soil near the pile is close to the experimental results, While there is a few different between simulation and experimental results with the growth of distance .Overall they coincide well with each other.

\section{2 vertical displacement}

In process of pile foundation engineering.There is a widespread concern over the issue that sunk pile cause ground heave .because ground heave severely destroys existed buildings. Figure 3-4, 3-5 are curves that in the process of piles pushed by static pressure vertical displacement with different depth of soil around the pile, changes with distance ' $r$ ' letf from pile's rim. From figure 3-4 around the upper pile, soil's displacement reaches maximum at the $40 \mathrm{~cm}$ distance from pile equaling to about 0.9 times diameter of the pile. The maximal displacement is $0.42 \mathrm{~cm}$ and about $9 \%$ of the pile's diameter. with the increase of distance from pile's rim, vertical displacement is sharply reduced and tends to zero .In the direction of depth, with the increase of depth, the vertical displacement gradually reduce, when the soil depth reaches the pile tip, closer from the pile, soil experience declining displacement in the figure 3-5,Main reason is this partial soil is strongly influenced by downward punching and shearing of the pile tip , at first particles declining displacement, and crowd adjacency , due to the limitation of secondarily adjacent soli bring out upward ground heave. Figure 3-7 is curves of the respective monitoring points' displacement at the $2 \mathrm{~cm}$ distance from the surface. Firstly ,closing to the pile' s rim ,monitoring points experience downward displacement, then particles move up under the upward extrusion。When distance $r$ leaving from pile's rim become larger, effect of upward punching and shearing on monitoring particles gradually weaken .monitoring particles produce light upward heave with mainly bearing lateral extrusion, the " $\mathrm{r}$ " greater ,the effect of upward extrusion weaker, and soil's vertical displacement also tends to zero.

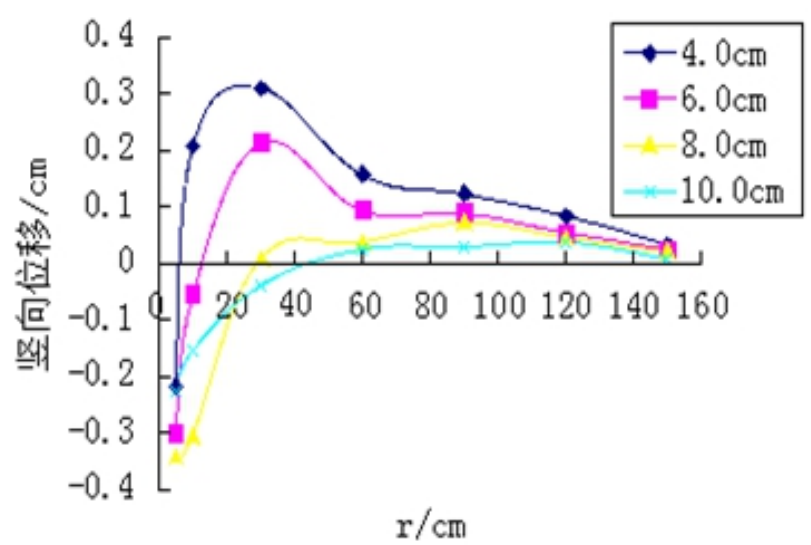

Figure 3-4 is the regular of vertical displacement of soil around upper pile along variation of the horizontal 


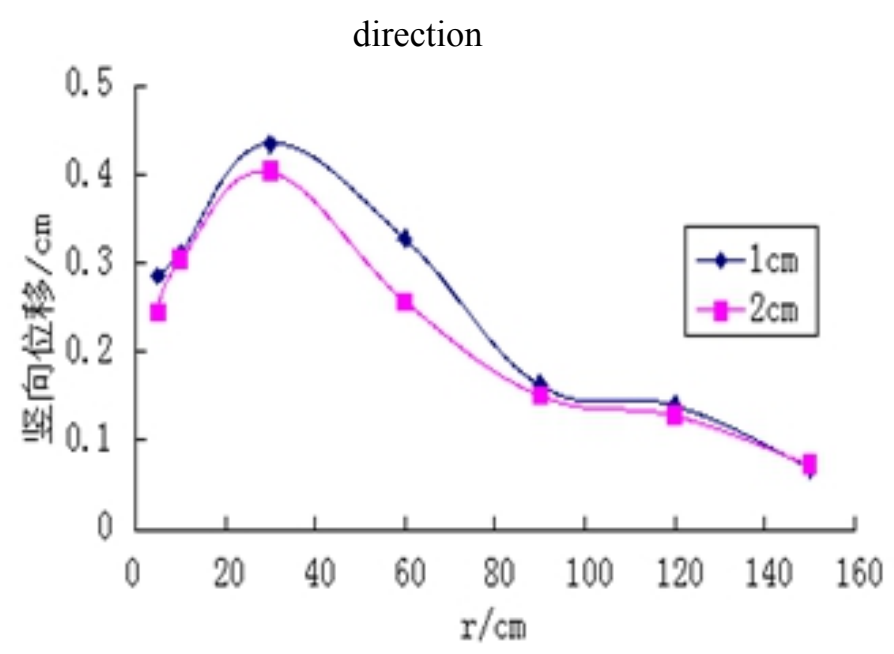

Figure 3-5 is the regular of vertical displacement of soil at tip of pile along variation of the horizontal direction

Figure 3-6 is regular that in the process of pile pause static pressure ,from the pile side with different distance, soil's vertical displacement changes with the direction of depth ,From the diagram, the closer to the pile, in the depth direction soil's vertical displacement gradually reduces with the increase of the depth .when reach a certain distance ,there was a downward displacement, from the figure , the maximal vertical displacement can be up to $0.32 \mathrm{~cm}$, about $7.1 \%$ of the pile's diameter, with depth continuing to increase, vertical displacement increase gradually from negative to zero. When increase of distance leaving from the pile's rim, in the depth direction, vertical displacement will decrease in the exponentially form and tends to zero.

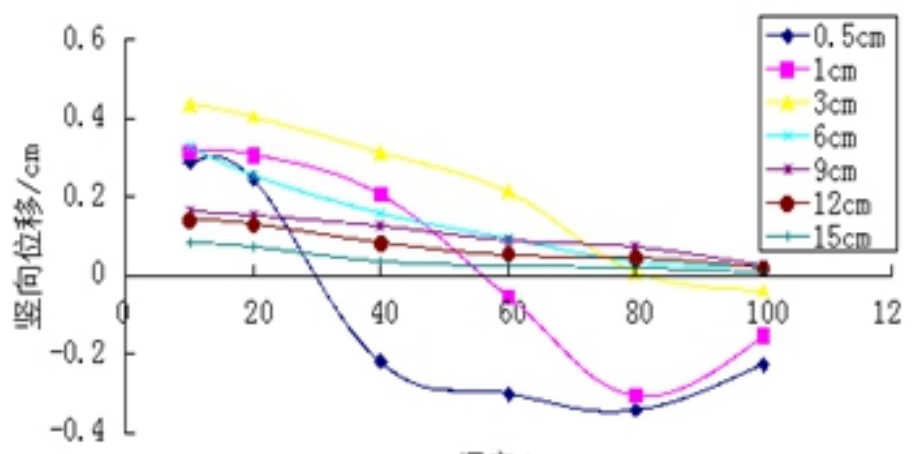

深度 $/ \mathrm{cm}$

Figure 3-6 is regular of vertical displacement of soil around the upper pile along variation of the horizontal horizontal direction

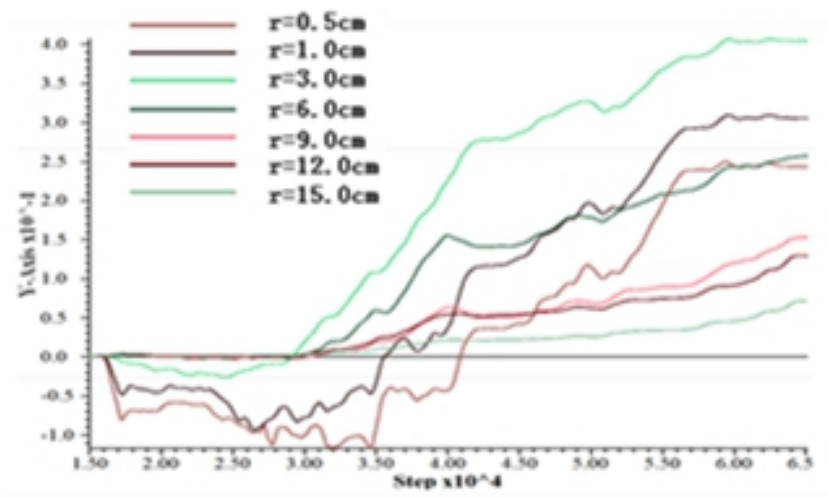

Figure3-7is curve of variation of respective monitoring points vertical displacement at $2 \mathrm{~cm}$ distance form ground surface 


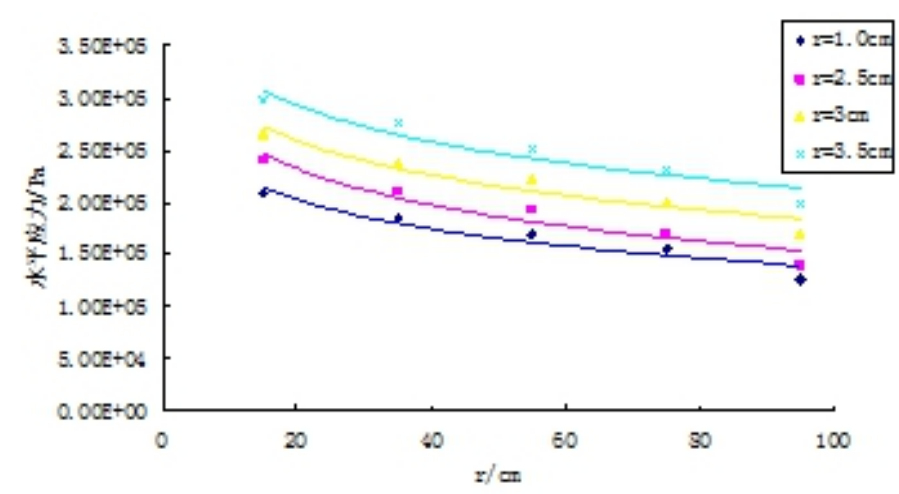

Figure 3-8 is regular of stress in the direction of axis $\mathrm{x}$ with variation of distance ' $\mathrm{r}$ ' leaving from pile's rim in

\subsection{Stress in the direction of axis $x$}

different depth of soil

Figure 3-8 is regular that with different depth of soil ,stress in the direction of axis $\mathrm{x}$ changes .From the diagram, the horizontal stress gradually increase along the direction of depth ,While horizontal stress gradually reduces with the increase of distance leaving from pile's rim.

\section{4 comparison of calculative result and experimental result}

$\mathrm{Xu}$ Jianpin[8] study on variation of soft clay displacement of soil with the method of indoor model test, in process of single pile pushed by static pressure, According to the regular of displacement, soil deformation zone is divided into three regions along the direction of depth,moreover the process of test and the method of soil sample preparation in detail are given, According to the regular of displacement, deformation of soil zone is divided into three regions along the direction of depth ,moreover the process of test and the method of soil sample preparation in detail are given ,In the process of experiment, adopt the method of double layer on the direct observation with readout microscope or eyes to measure the movement of displacement observation points, and get the ruler of displacement of soil variation alone the direction of horizon and the depth as shown in lower tracing. Contrasting ahead simulative results of the particle flow, which can explain PFC2D program can simulate well the effect of compacted soil in the process of pile paused by static pressure .

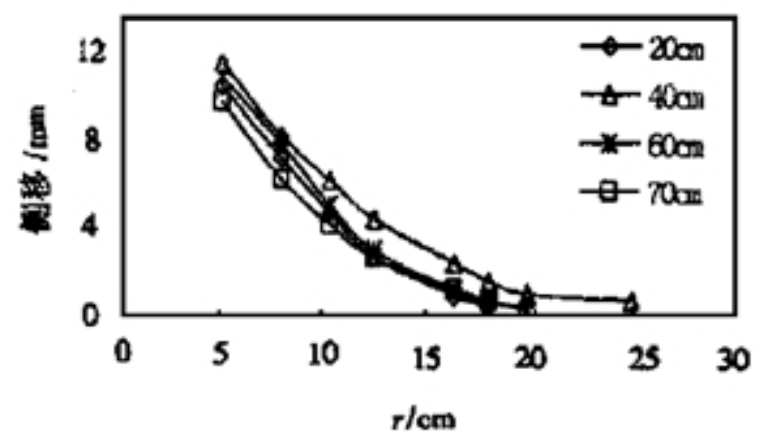

(a) Curve of lateral displacement of the soil around tip of pile along the variation of the radial direction

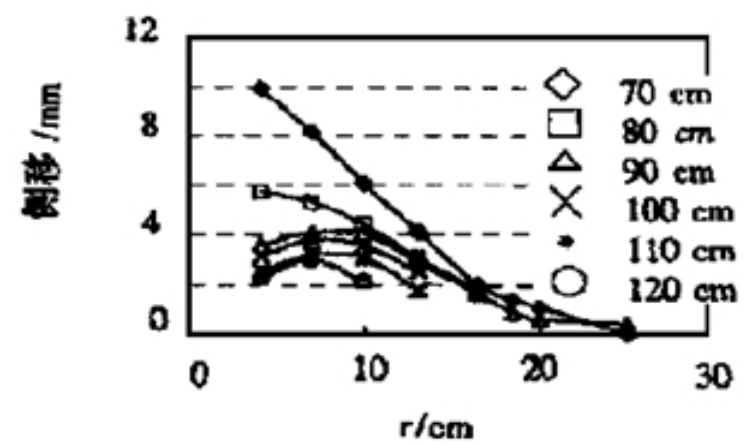

(b) Curve of lateral displacement of soil around the upper plie along the variation of the radial direction 


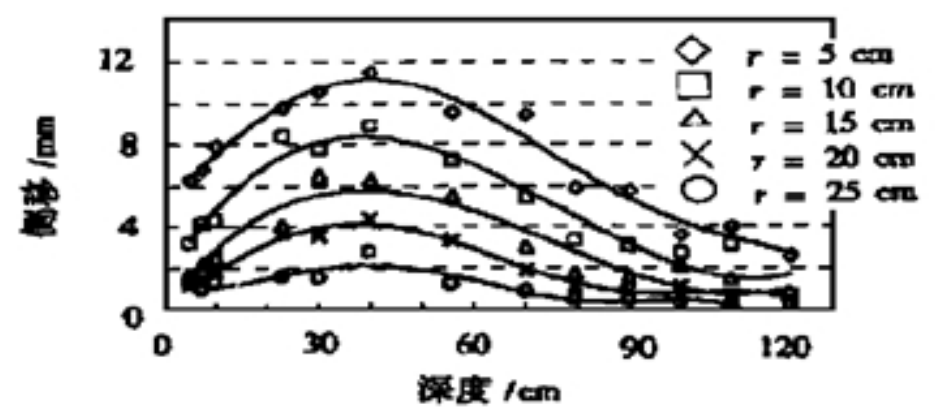

(c)Curve of lateral displacement of soil around pile around pile along the variation of direction of depth

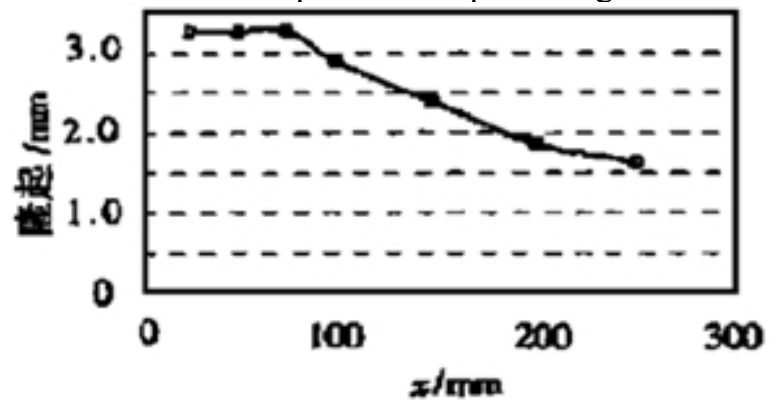

(d) Regular of Vertical soil of displacement around upper pile along the variation of horizontal direction

\section{Conclusion}

(1)according to the study, PFC2D program can simulate well the compaction effect in the process of static pressure pile. PFC2D research from the Angle of the mesoscopic static pressure pile compaction mechanism, to overcome the large deformation, material nonlinearity and finite element method can't simulate continuous injection pile soil medium a series of problems, and in the modeling process of middle-earth constitutive relation not nominated, simply give particles related parameters, simple modeling process, model feature is more consistent with the actual working condition;

(2)the analysis results and the theoretical analysis and experimental results coincide degree is high. Pile driving process models used in the whole process of particle movement, combined with the stress and displacement curve, the result with the expansion and the cylindrical cavity expansion theory is consistent;

(3) the research from the perspective of mesoscopic reveals the change rule of stress and displacement in the process of pile driving. Pile soil particle displacement is: the overall process of pile soil particles due to the cutting down of pile tip and soil particles between the cohesive force by a downward displacement, and then produced under the action of a pile of lateral displacement, at the same time by time limit effect of upward uplift of surrounding soils.

\section{References}

[1]BishopRF, Hill RMott N F. Theory of indentation and hardness tests [C]. Proceedings of the Physical Society, London, 1945, 57( 1) : 147-159.

[2]Vesic A S. Expansion of cavity in infinite soil mass [J]. Journal of the Soil Mechanics and Foundation Division, 1972, 98( 3) :265-289.

[3]Zhan,Y.X. et al. (2013). Study of process of open-ended pipe pile driven into sand soil by particle flow simulation [J]. Journal of geotechnical engineering.

[4]Luo,Z.Y et al..(2008). Comparative study of dynamic simulation for compacting displacement of jacked pile and in-situ test $[\mathrm{J}]$. Journal of rock mechanics and engineering.

[5]Zhou,H et al..(2014). Study on pile sinking compaction effect of hydrostatic wedge pile using cavity expansion theory[J]. China journal of highway and transport.

[6]Yao,Z,M (2014)Static pressure pile expansion theory research and numerical simulation analysis[D]. Guangdong university of technology .

[7] Meyerhof G.G(1959 )..Compaction of sands and bearing capacity of piles[ J] .J.S .M .F .D .ASCE, 
1959,85 .

[8]Xu,J.P(2000). Model test research on pile driving effect of squeezing against soil[J]. Rock and soil mechanics.

[9] Butterfield R., Baberjee P.K. Application of electro-osmo-sis to soil part2 [A] .Civil Engineering Research Report[R] .UK:Department of Civil Engineering, Southampton University .

[10] Butterfield R., Banerjee P.K(1989). The effects of pore water pressure on the capacity of driven piles[ A] .2nd South East Asia Regional Conference on Soil Mechanics and Foundation Engineering [C] , Hong Kong . 